\title{
Animal-Visitor Interactions: Effects, Experiences, and Welfare
}

\author{
Eduardo J. Fernandez ${ }^{1 *}$ and Samantha J. Chiew ${ }^{2,3}$
}

\author{
${ }^{1}$ School of Animal and Veterinary Sciences, The University of Adelaide \\ ${ }^{2}$ Animal Welfare Science Centre, Faculty of Veterinary and Agricultural Sciences, \\ The University of Melbourne, (iD https://orcid.org/0000-0003-2514-1136 \\ ${ }^{3}$ Animal Welfare Section, Agricultural Policy Division, Department of Agriculture, Water and the Environment, Canberra, \\ ACT, Australia \\ *Corresponding author (edjfern@gmail.com) iD https://orcid.org/0000-0001-5444-6604
}

Citation - Fernandez, E.J., \& Chiew, S.J. (2021). Animal-Visitor interactions: Effects, experiences, and welfare. Animal Behavior and Cognition, 8(4), 462-467. https://doi.org/10.26451/abc.08.04.01.2021

\begin{abstract}
Animal-Visitor Interactions (AVI) within zoos and aquariums have become an increasingly studied topic. Influenced by both the broader field of Human-Animal Interactions (HAI), as well as visitor studies conducted in museums, AVI studies can be separated into two areas of focus: (1) Visitor effects, or the impact visitors have on the animals housed within a zoo, and (2) visitor experiences, or the impact zoo animals and visiting a zoo have on the visitors. Historically, visitor effects have been of primary concern to the study of AVIs, as have the potential negative impacts on the welfare of animals, particularly those of zoo primates. This special issue examines the impact of AVIs in greater detail through twelve recent papers on the topic, equally addressing visitor effects and experiences. Many of the papers focus on positive welfare indices, as well as less traditional measures to examine both visitor effects and experiences, such as visitor proximity and visitor interviews. In addition, we discuss the relevance of future AVI work, with particular attention to (a) increased interest in visitor experience research, (b) examinations of signage effects, and (c) continued focus on positive welfare indices and direct interactions, such as public feedings.
\end{abstract}

Keywords: animal welfare; animal-visitor interactions; human-animal interactions; visitor effects; visitor experiences; visitor studies

The study of Animal-Visitor Interactions (AVI) in zoos and aquariums has steadily increased over the past several decades. The field can be considered a branch of Human-Animal Interactions (HAI), which itself includes studies of Human-Animal Relationships (HAR) or Human-Animal Bonds (HAB; Hosey \& Melfi, 2014), research with livestock (Hemsworth, 2003), and therapeutic interventions or treatments for people that involve companion or other animals (e.g., Animal-Assisted Therapy [AAT]; APA, 2021; Griffin et al., 2019). In addition, the study of AVIs have been greatly influenced by visitor studies, including those conducted in the field of museology (i.e., museum studies; Kirchberg \& Tröndle, 2012), as well as those conducted in zoos (Bitgood \& Shettel, 1996; Davey, 2006; Fernandez, 2019).

To date, five major reviews on the topic of AVIs in zoos have been conducted (Davey, 2007; Fernandez et al., 2009; Godinez \& Fernandez, 2019; Hosey, 2000; Sherwen \& Hemsworth, 2019). In addition, researchers have reviewed specific variables related to AVIs, including the potential enrichment/welfare benefits of AVIs (Claxton, 2011), husbandry or other animal training procedures as a form of enrichment (Fernandez, 2021), ethical considerations for AVIs (Learmonth, 2020), the effects of zoo visitors on primates (Hosey, 2005), and the rates and types of AVIs that occur in zoos and aquariums (D'Cruze et al., 2019). Contrary to much of the study of HAIs outside of zoos, AVIs have primarily focused on the effects of humans on animals, a term Hosey (2000) called "visitor effects." Much of this early AVI research identified negative visitor effects on zoo animals, and was focused 
primarily on primates (Davey, 2007; Fernandez et al., 2009; Hosey, 2000; Hosey, 2005). Hosey (2000) also identified possible changes in zoo animals because of visitor effects being (1) stressful or otherwise negative, (2) enriching or otherwise positive, or (3) neutral or otherwise unclear effects (e.g., social facilitation). Finally, Hosey (2000) identified a feature of AVIs that continues to be problematic for both AVI and HAI research: The extent to which we can attribute changes observed in animals as being caused by visitor activity or vice versa.

Fernandez et al. (2009) were the first to review both the visitor effect (visitor effects on zoo animals), and the impact of zoo animals on visitors, a variable that would later fall under the larger concept of "visitor experiences." Godinez and Fernandez (2019) would further detail visitor experiences by reviewing the relationship between visiting a zoo and its influence on visitor behaviors and perceptions, as well as the way zoo visits impact zoo conservation efforts. Sherwen and Hemsworth (2019) have more recently updated our understanding of the visitor effect, including research that extends beyond that of primates and identifies positive or enriching effects because of those AVIs.

\section{Our Animal-Visitor Interaction Special Issue}

This special issue of Animal Behavior and Cognition focuses on current research examining AVIs in zoos and aquariums. Twelve papers are included in this volume that examine both visitor effects and visitor experiences. We begin the first half of the special issue with studies on visitor effects. O'Malley et al. (2021) studied the effects of visitor viewing access on a troop of Western lowland gorillas (Gorilla gorilla gorilla). Both behavioral and physiological measures (via fecal samples) were recorded in response to whether visitors had full or partial viewing access. Wascher et al. (2021) examined the behavioral responses of common ravens (Corvus corax) and crows (Corvus corone) under conditions when visitors were close, far, or absent. Ramont et al. (2021a) studied the behavioral effects of number of visitors, proximity of visitors, and visitor interaction style in relation to petting zoo-housed domestic goats (Capra hircus). Edes et al. (2021) assessed the effects of crowd size, composition, and noise level on the swimming activity of king (Aptenodytes patagonicus), gentoo (Pygoscelis papua), and southern rockhopper (Eudyptes chrysocome) penguins. Jones et al. (2021) explored the effects of visitor presence and crowd size on red kangaroo (Macropus rufus) behavior with respect to a COVID19 zoo closure. Finally, Bernstein-Kurtycz et al. (2021) examined the effects of zoo visitor density and seasonality on the behaviors of five species of zoo-housed bears: sloth bears (Melursus ursinus), Andean bears (Tremarctos ornatus), grizzly bears (Ursus arctos horribilis), American black bears (Ursus americanus), and a Malayan sun bear (Helarctos malayanus).

The second half of the special issue focuses on studies of visitor experiences. Rank et al. (2021) examined the effects of animal ambassador programs and facilitation style on zoo visitors. Observations and direct interviews with visitors were measured during zoo visits. Lugosi and Lee (2021) studied the effects of using Virtual Reality (VR) as an engagement and educational tool for zoo visitors. Qualitative, semi-structured interviews were used to examine zoo visitor learning from an African wild dog (Lycaon pictus) VR experience. Zager and Jensvold (2021) studied the effects of signs and docents on zoo visitor education. The presence of signs, docents, or neither were examined in terms of their ability to educate about desired visitor behaviors at a Chimpanzee (Pan troglodytes) enclosure. Perdue and Robinson (2021) explored the effects of educational videos on the zoo visitor experience. Videos detailing cognitive research or environmental enrichment with sun bears, as well as a no video condition, were examined for their impact on zoo visitor knowledge and attitudes gathered from surveys, as well as visitor behavior, such as time spent at a zoo sun bear enclosure. Muller et al. (2021) examined the effects of visitors' general perceptions of zoos and animals on their perceptions of the behavior of other visitors at the zoo. Both surveys and observations of visitors were used to assess visitor beliefs about the purpose of zoos and how they related to their perceptions of the actions displayed by other visitors towards zoo animals. Finally, Learmonth et al. (2021) reviewed research related to the behaviors, attitudes, perceptions, and learning of zoo visitors. This is the second visitor experience-focused AVI review paper (preceded by Godinez \& Fernandez, 2019), and the first review to consider these effects from a general, non-conservation-focused perspective. 


\section{The Future of Animal-Visitor Interactions Research}

Animal-visitor interactions in zoos and aquariums continue to adapt to applied animal behavior and welfare research interests. This special issue represents some of those recent trends, with studies that equally examine both visitor effects and experiences, as well as a focus on potential positive welfare indicators for both zoo animals and visitors alike. We expect this trend to continue, as most modern zoos are demonstrating increased interest in the use and impact of AVIs, including direct interactions, to assess and improve animal welfare and visitor learning. For instance, D'Cruze et al. (2019) found that, of over 1,200 zoo and aquarium websites reviewed from across the globe, 929 of the facilities (75\%) listed some type of intentional and direct animal interaction, such as petting zoos or feeding interactions, offered to the public, and almost half $(n=587 ; 47 \%)$ included two or more types of direct interactions. Therefore, we end our introduction to the special issue with three aspects of AVIs worth considering for future research: (1) increased interest in visitor experience research, (2) examinations of signage effects, and (3) continued focus on positive welfare indices and direct interactions, such as public feedings.

\section{Increased Interest in Visitor Experiences Research}

One unique feature of this special issue is the equal emphasis placed on papers addressing either visitor effects or visitor experiences. Most previous AVI research and reviews focused on visitor effects. For example, of the five major AVI reviews previously listed, three of those reviews focused exclusively on visitor effects (Davey, 2007; Hosey, 2000; Sherwen \& Hemsworth, 2019), one of the papers reviewed both visitor effects and experiences (Fernandez et al., 2009), and only one of the five papers focused exclusively on visitor experiences (Godinez \& Fernandez, 2019). We hope that future research will focus more directly on visitor experiences, including the need for comparisons of zoo visitor experiences to those of non-zoo visitors (Fernandez, 2019), and further examination of the perceptions and attitudes of visitors that may influence the way people behave toward zoo animals (Chiew et al., 2021). In addition, we hope that future research will focus on unique measures to examine some of the issues relevant to visitor experiences, including those that incorporate modern technology. For instance, Fukano et al. (2021) recently used internet activity, including tweets, to examine the debut of an endangered bird species in zoos. Measures such as internet activity are ideal for both visitor/non-visitor comparisons and visitor attitudes/perceptions studies, which should also allow zoos to assess the potential outcomes that different types of enclosures and zoo experiences have on their conservation efforts.

\section{Examinations of Signage Effects}

With the study of visitor effects on the welfare of animals, the use of signs to modify visitor activity is an essential component for understanding and improving AVIs. However, very little research has looked to experimentally modify this variable, with two of the few studies conducted in zoos occurring decades ago (Bitgood et al., 1988; Kratochvil \& Schwammer, 1997). Only recently have several more studies on the topic been published (Chiew et al., 2019; Dancer \& Burn, 2019; Sherwen et al., 2014), with the newest publication included within this special issue (Zager \& Jensvold, 2021). Given the ease with which modification of signage can be implemented, along with the applied importance of signage for both improving visitor education and managing visitor behavior, signage research should play an important role for both future visitor effects and experiences research.

\section{Positive Welfare Indices and Public Feedings}

As noted in recent AVI reviews (Sherwen \& Hemsworth, 2019), as well as by the papers published in this special issue, AVIs have increasingly examined potential positive welfare benefits for both zoo animals and visitors. Our understanding of positive indicators of animal welfare have become a more recent focal point for all applied animal work, including those that extend to all human-animal interactions (Mellor, 2016; Mellor \& Beausoleil, 2015; Mellor et al., 2020). Such efforts, along with the increasing trend in providing direct animal interactions to zoo visitors (D'Cruze et al., 2019), suggest 
that certain types of activities, such as managed public feedings, could provide an ideal way for zoos to incorporate AVIs that simultaneously benefit the welfare of the animals and education of visitors. Only a handful of studies have examined the impacts of public feedings (Collins et al., 2017; Farrand et al., 2014; Orban et al., 2016). In addition, Jones et al. (2016) and Ramont et al. (2021b) have experimentally demonstrated little to no adverse effects to zoo lemurs and petting zoo chickens resulting from direct public feeding interactions, respectively. Most recently, Fernandez et al. (2021) demonstrated positive welfare changes to zoo-housed elephants resulting from public feeding interactions. While public feedings are just one example of a means to assess and improve positive welfare measures associated with AVIs, they show considerable promise for future AVI research. They provide all the necessary variables for examining both visitor effects and visitor experiences, enable the ability to experimentally differentiate between the impact of visitors on animals and vice versa, and have the potential to simultaneously enrich the lives of zoo animals and visitors.

\section{Animal-Visitor Interactions - Summing Up}

Animal-visitor interaction studies are an important part of welfare research conducted in modern zoos and aquariums. In this sense, welfare can be defined in relation to the lives of the animals residing within a zoo, as well as the impact they have for the people visiting such a facility. Zoos offer an ideal setting to understand all components of human-animal interactions, which necessarily means understanding the effects people visiting a zoo have on the residing animals and the experiences created by visitors observing and/or interacting with zoo animals. AVIs provide a unique lens for understanding and improving our zoo welfare efforts. We hope this special issue is just one step to advancing such efforts.

\section{Author Note}

This work received no funding, and we have no known conflicts of interest to disclose. The manuscript was edited and accepted by Dr. Jennifer Vonk, since both authors were the Guest Editors of the special issue in which this manuscript is published.

\section{References}

American Psychological Association (2021). Human-Animal Interaction, APA Division 17, Section 13. Retrieved September $29^{\text {th }}, 2021$ from https://www.apa-hai.org/

Bernstein-Kurtycz, L. M., Koester, D., Snyder, R., Vonk, J., Willis, M., \& Lukas, K. (2021). 'Bearly' changing with the seasons: Bears of five species show few behavioral changes across seasons and at varying visitor densities. Animal Behavior and Cognition, 8(4), 538-557. https://doi.org/10.26451/abc.08.04.07.2021

Bitgood, S., Carnes, J., Nabors, A., \& Patterson, D. (1988). Controlling public feeding of zoo animals. Visitor Behavior, 2(4), 6.

Bitgood, S., \& Shettel, H. H. (1996). An overview of visitor studies. Journal of Museum Education, 21(3), 6-10. https://doi.org/10.1080/10598650.1996.11510329

Chiew, S. J., Butler, K. L., Sherwen, S. L., Coleman, G. J., Fanson, K. V., \& Hemsworth, P. H. (2019). Effects of regulating visitor viewing proximity and the intensity of visitor behaviour on little penguin (Eudyptula minor) behaviour and welfare. Animals, 9(6), 285. https://doi.org/10.3390/ani9060285

Chiew, S. J., Hemsworth, P. H., Melfi, V., Sherwen, S. L., Burns, A., \& Coleman, G. J. (2021). Visitor attitudes towards little penguins (Eudyptula minor) at two Australian zoos. Frontiers in Psychology, 12, 626185. https://doi.org/10.3389/fpsyg.2021.626185

Claxton, A. M. (2011). The potential of the human-animal relationship as an environmental enrichment for the welfare of zoo-housed animals. Applied Animal Behaviour Science,133(1-2), 1-10. https://doi.org/10.1016/j.applanim.2011.03.002

Collins, C., Corkery, I., Haigh, A., McKeown, S., Quirke, T., \& O'Riordan, R. (2017). The effects of environmental and visitor variables on the behavior of free-ranging ring-tailed lemurs (Lemur catta) in captivity. Zoo Biology, 36(4), 250-260. https://doi.org/10.1002/zoo.21370

D’Cruze, N., Khan, S., Carder, G., Megson, D., Coulthard, E., Norrey, J., \& Groves, G. (2019). A global review of animal-visitor interactions in modern zoos and aquariums and their implications for wild animal welfare. Animals, 9(6), 332. https://doi.org/10.3390/ani9060332 
Dancer, A. M., \& Burn, C. C. (2019). Visitor effects on zoo-housed Sulawesi crested macaque (Macaca nigra) behaviour: Can signs with 'watching eyes' requesting quietness help? Applied Animal Behaviour Science, 211, 88-94. https://doi.org/10.1016/j.applanim.2018.12.005

Davey, G. (2006). Visitor behavior in zoos: A review. Anthrozoös, 19(2), 143-157. https://doi.org/10.2752/089279306785593838

Davey, G. (2007). Visitors' effects on the welfare of animals in the zoo: A review. Journal of Applied Animal Welfare Science, 10(2), 169-183. https://doi.org/10.1080/10888700701313595

Edes, A. N., Baskir, E., Bauman, K. L., Chandrasekharan, N., Macek, M., \& Tieber., A. (2021). Effects of crowd size, composition, and noise level on pool use in a mixed-species penguin colony. Animal Behavior and Cognition, 8(4), 507-520. https://doi.org/10.26451/abc.08.04.05.2021

Farrand, A., Hosey, G., \& Buchanan-Smith, H. M. (2014). The visitor effect in petting zoo-housed animals: Aversive or enriching? Applied Animal Behaviour Science, 151, 117-127. https://doi.org/10.1016/j.applanim.2013.11.012

Fernandez, E. J. (in press). Training as enrichment: A critical review. Animal Welfare.

Fernandez, E. J. (2019). What are we doing to measure conservation support from zoo visitors? AZA Conservation Education Committee Newsletter, 13(2), 14-15.

Fernandez, E. J., Tamborski, M. A., Pickens, S. R., \& Timberlake, W. (2009). Animal-visitor interactions in the modern zoo: Conflicts and interventions. Applied Animal Behaviour Science, 120(1-2), 1-8. https://doi.org/10.1016/j.applanim.2009.06.002

Fernandez, E. J., Upchurch, B., \& Hawkes, N. C. (2021). Public feeding interactions as enrichment for three zoohoused elephants. Animals, 11(6), 1689. https://doi.org/10.3390/ani11061689

Fukano, Y., Soga, M., Fukuda, M., Takahashi, Y., Koyama, M., Arakawa, Y., Miyano, N., Akiba, Y., \& Horiguchi, M. (2021). Debut of an endangered bird in zoos raises public interest, awareness and conservation knowledge of the species. Animal Conservation (early view). https://doi.org/10.1111/acv.12693

Godinez, A. M., \& Fernandez, E. J. (2019). What is the zoo experience? How zoos impact a visitor's behaviors, perceptions, and conservation efforts. Frontiers in Psychology, 10, 1746. https://doi.org/10.3389/fpsyg.2019.01746

Griffin, J. A., Hurley, K., \& McCune, S. (2019). Human-animal interaction research: Progress and possibilities. Frontiers in Psychology, 10, 2803. https://doi.org/10.3389/fpsyg.2019.02803

Hemsworth, P. H. (2003). Human-animal interactions in livestock production. Applied Animal Behaviour Science, 81(3), 185-198. https://doi.org/10.1016/S0168-1591(02)00280-0

Hosey, G. R. (2000). Zoo animals and their human audiences: What is the visitor effect? Animal Welfare, 9(4), 343-357.

Hosey, G. R. (2005). How does the zoo environment affect the behaviour of captive primates? Applied Animal Behaviour Science, 90(2), 107-129. https://doi.org/10.1016/j.applanim.2004.08.015

Hosey, G., \& Melfi, V. (2014). Human-animal interactions, relationships and bonds: A review and analysis of the literature. International Journal of Comparative Psychology. https://doi.org/10.46867/ijcp.2014.27.01.01

Jones, H., McGregor, P. K., Farmer, H. L. A., \& Baker, K. R. (2016). The influence of visitor interaction on the behavior of captive crowned lemurs (Eulemur coronatus) and implications for welfare. Zoo Biology, 35(3), 222-227. https://doi.org/10.1002/zoo.21291

Jones, M., Gartland, K. N., \& Fuller, G. (2021). Effects of visitor presence and crowd size on zoo-housed red kangaroos (Macropus rufus) during and after a COVID-19 closure. Animal Behavior and Cognition, 8(4), 521-537. https://doi.org/10.26451/abc.08.04.06.2021

Kirchberg, V., \& Tröndle, M. (2012). Experiencing exhibitions: A review of studies on visitor experiences in museums. Curator: The Museum Journal, 55(4), 435-452. https://doi.org/10.1111/j.2151-6952.2012.00167.x

Kratochvil, H., \& Schwammer, H. (1997). Reducing acoustic disturbances by aquarium visitors. Zoo Biology, 16(4), 349-353. https://doi.org/10.1002/(SICI)1098-2361(1997)16:4<349::AID-ZOO7>3.0.CO;2-A

Learmonth, M. J. (2020). Human-animal interactions in zoos: What can compassionate conservation, conservation welfare and duty of care tell us about the ethics of interacting, and avoiding unintended consequences? Animals, 10(11), 2037. https://doi.org/10.3390/ani10112037

Learmonth, M. J., Chiew, S. J., Godinez, A. M., \& Fernandez, E. J. (2021). Animal-visitor interactions and the visitor experience: Visitor behaviors, attitudes, perceptions, and learning in the modern zoo. Animal Behavior and Cognition, 8(4) 632-649. https://doi.org/10.26451/abc.08.04.13.2021

Lugosi, Z., \& Lee, P. C. (2021). A case study exploring the use of Virtual Reality in the zoo context. Animal Behavior and Cognition, 8(4), 576-588. https://doi.org/10.26451/abc.08.04.09.2021 
Mellor, D. J. (2016). Updating animal welfare thinking: Moving beyond the "Five Freedoms" towards "a Life Worth Living.” Animals, 6(3), 21. https://doi.org/10.3390/ani6030021

Mellor, D. J., \& Beausoleil, N. J. (2015). Extending the 'Five Domains' model for animal welfare assessment to incorporate positive welfare states. Animal Welfare, 24(3), 241. https://doi.org/10.7120/09627286.24.3.241

Mellor, D. J., Beausoleil, N. J., Littlewood, K. E., McLean, A. N., McGreevy, P. D., Jones, B., \& Wilkins, C. (2020). The 2020 five domains model: Including human-animal interactions in assessments of animal welfare. Animals, 10(10), 1870. https://doi.org/10.3390/ani10101870

Muller, S. L., Bissell, S. L., Cunningham, K. M., \& Strasser, R. (2021). How do you behave at the zoo? A look at visitor perceptions of other visitors' behavior at the zoo. Animal Behavior and Cognition, 8(4), 619-631. https://doi.org/10.26451/abc.08.04.12.2021

O’Malley, M., Woods, J. M., Byrant, J., \& Miller, L. J. (2021). How is Western lowland gorilla (Gorilla gorilla gorilla) behavior and physiology impacted by $360^{\circ}$ visitor viewing access? Animal Behavior and Cognition, 8(4), 468-480. https://doi.org/10.26451/abc.08.04.02.2021

Orban, D. A., Siegford, J. M., \& Snider, R. J. (2016). Effects of guest feeding programs on captive giraffe behavior. Zoo Biology, 35(2), 157-166. https://doi.org/10.1002/zoo.21275

Perdue, B. M., \& Robinson, B. (2021). Does exposure to animal cognition research influence the zoo visitor experience? Animal Behavior and Cognition, 8(4), 601-618. https://doi.org/10.26451/abc.08.04.11.2021

Ramont, M., Leahy, M., \& Cronin, K. A. (2021a). Domestic animal welfare at the zoo: The impact of an animal visitor interaction program on chickens. Animal Behavior and Cognition,8(1), 1-14. https://doi.org/10.26451/abc.08.01.01.2021

Ramont, M., Leahy, M., \& Cronin, K. A. (2021b). The welfare of domestic goats (Capra hircus) in a zoo-based animal-visitor interaction program. Animal Behavior and Cognition, 8(4), 493-506. https://doi.org/10.26451/abc.08.04.04.2021

Rank, S. J., Roberts, S., \& Manion, K. (2021). The impact of ambassador animal facilitated programs on visitor curiosity and connections: A mixed methods study. Animal Behavior and Cognition, 8(4), 558-575. https://doi.org/10.26451/abc.08.04.08.2021

Sherwen, S. L., \& Hemsworth, P. H. (2019). The visitor effect on zoo animals: Implications and opportunities for zoo animal welfare. Animals, 9(6), 366. https://doi.org/10.3390/ani9060366

Sherwen, S. L., Magrath, M. J., Butler, K. L., Phillips, C. J., \& Hemsworth, P. H. (2014). A multi-enclosure study investigating the behavioural response of meerkats to zoo visitors. Applied Animal Behaviour Science, 156, 70-77. https://doi.org/10.1016/j.applanim.2014.04.012

Wascher, C. A. F., Baur, N., Hengl, M., Köck, C., Pegger, T., Schindlbauer, J., \& Wemer, L. (2021). Behavioural responses of captive corvids to the presence of visitors. Animal Behavior and Cognition, 8(4), 481-492. https://doi.org/10.26451/abc.08.04.03.2021

Zager, L. N., \& Jensvold, M. L. A. (2021). Signs and docents in zoo visitor education: Using affinitive chimpanzee (Pan troglodytes) behaviors. Animal Behavior and Cognition, 8(4) 589-600. https://doi.org/10.26451/abc.08.04.10.2021 